\title{
Characteristics of Natural Killer Cells in Malaysian HIV Patients Presenting with Immune Restoration Disease After ART
}

\author{
Dino Bee Aik Tan ${ }^{1 *}$, Yean Kong Yong ${ }^{2}$, Hong Yien Tan², Martyn French ${ }^{1,3}$, Adeeba Kamarulzaman² and Patricia Price ${ }^{1,3}$ \\ ${ }^{1}$ School of Pathology and Laboratory Medicine, University of Western Australia, Perth, Western Australia, Australia \\ ${ }^{2}$ Centre of Excellence for Research in AIDS (CERiA), University of Malaya, Kuala Lumpur, Malaysia \\ ${ }^{3}$ Department of Clinical Immunology, Royal Perth Hospital, Perth, Western Australia, Australia
}

\begin{abstract}
Objectives: Natural killer (NK) cell function was investigated in Malaysian HIV patients beginning antiretroviral therapy (ART) with advanced immunodeficiency. Some patients experienced immune restoration disease (IRD) presenting as exacerbations of pre-existing infections. Whilst most IRD are attributed to interferon-gamma (IFN $\gamma$ ) produced by T-cells, NK cells may also contribute.

Methods: Blood leukocytes were collected prospectively from $100 \mathrm{HIV}$ patients over 1 year on ART, plus 36 healthy controls. Eleven patients who experienced an IRD and 14 matched controls were assayed. Cells producing IFN $\gamma$ were quantitated by ELISpot after stimulation with an NK target (K562 cells) or antigens from pathogens associated with the IRD. NK cell subsets, CD16 and perforin expression were determined by flow cytometry.

Results: NK cell IFN $\gamma$ responses were lower in HIV patients at baseline $(p<0.001)$, improved by Week $24(p<0.01)$ but remained lower than uninfected controls $(p<0.05)$. Proportions of CD56 ${ }^{\text {hi }}$ NK cells increased $(p<0.01)$ above controls at Week 24. Perforin expression on these cells was higher than controls at baseline $(p<0.01)$, but declined on ART. Proportions of $\mathrm{CD}_{56}{ }^{\text {lo }} \mathrm{NK}$ cells were similar in patients and controls throughout. IRD patients showed lower CD16 expression on $\mathrm{CD}^{\mathrm{lo}}{ }^{\text {I0 }} \mathrm{NK}$ cells than non-IRD patients before treatment $(p<0.05)$
\end{abstract}

Conclusions: NK cells profiles were restored on ART, but NK cell IFN $\gamma$ production remained impaired. Low CD16 expression on $\mathrm{CD}_{5} 6^{\text {lo }} \mathrm{NK}$ cells may mark a predisposition for an IRD.

Keywords: Antiretroviral therapy; HIV; Immune restoration disease; Natural killer cells

\section{Introduction}

Chronic human immunodeficiency virus (HIV) infection is characterized by defects in the immune system including depletion of $\mathrm{CD}^{+}{ }^{+} \mathrm{T}$-cells and impaired T-cell function. Successful antiretroviral therapy (ART) suppresses viral replication. The subsequent recovery of T-cell responses and the decline of opportunistic infections are well documented.

Natural killer (NK) cells are part of the innate immune system and can secrete T-helper 1 (Th1)-associated pro-inflammatory cytokines like interferon-gamma (IFN $\gamma$ ) and tumor necrosis factor-alpha (TNF $\alpha$ ). NK cells are important in controlling tumors and cytomegalovirus (CMV), mycobacterial and fungal infections [1-4]. Effects of untreated HIV disease on NK cells include depletion of the large CD56 $6^{\text {lo }} \mathrm{NK}$ subset, expansion of a dysfunctional $\mathrm{CD} 56^{\text {neg }} \mathrm{CD} 16^{+}$NK subset, functional abnormalities and perturbation of the NK cell receptor repertoire [5-8].

Studies of the restoration of NK cell functions after ART have yielded inconsistent results [9-12]. We reported that NK cell IFN $\gamma$ responses and proportions of CD56 ${ }^{\text {lo }} \mathrm{NK}$ cells are lower in Caucasian HIV patients on long-term ART (2-5 years) than in healthy controls [13]. However, no previous studies of NK cells in HIV disease have considered Asian populations. This is important because Asian patients are typically younger and affected by more opportunistic infections than Caucasians [14,15]. Moreover genetic profiles pertinent to NK cells vary with ethnicity [16].

In a subset of patients, a favorable virological response to ART is accompanied by an atypical presentation of diseases associated with pre-existing opportunistic pathogens $[17,18]$. These are known as immune restoration disease (IRD) or immune reconstitution inflammatory syndrome (IRIS). IRD associated with Mtb and Cryptococcus neoformans parallel robust IFN $\gamma$ responses evident in vitro following stimulation of blood leukocytes with relevant antigens [19-22]. These are attributed to CD4 ${ }^{+}$T-cells but monocytes and NK cells may contribute if stimulated via pattern recognition receptors (PRR).

Less is known about the immuno-pathogenesis of IRD associated with herpes viruses [CMV or Varicella Zoster Virus (VZV)]. Caucasian HIV patients with CMV IRD had higher numbers of activating Killer Immunoglobulin-like Receptor (KIR) genes than non-IRD patients or healthy controls [23]. KIR are expressed by all NK cells and some $\mathrm{CD}^{+} \mathrm{T}$-cells $[24,25]$. High numbers of activated NK cells were found in the cerebral spinal fluid of a patient with VZV IRD presenting as transverse myelitis [26]. Together, these results suggest NK cells may contribute to viral IRD.

*Corresponding author: Dino Bee Aik Tan, School of Pathology and Laboratory Medicine, University of Western Australia, Level 2, Medical Research Foundation Building, Royal Perth Hospital, Rear of 50 Murray Street, Perth, WA 6000, Australia, Tel: 618-92240270; Fax: 618-92240204; E-mail: dtan@meddent.uwa.edu.au

Received October 03, 2010; Accepted October 15, 2010; Published October 18, 2010

Citation: Tan DBA, Yong YK, Tan HY, French M, Kamarulzaman A, et al. (2010) Characteristics of Natural Killer Cells in Malaysian HIV Patients Presenting with Immune Restoration Disease After ART. J AIDS Clinic Res 1:102 doi:10.4172/2155-6113.1000102

Copyright: @ 2010 Tan DBA, et al. This is an open-access article distributed under the terms of the Creative Commons Attribution License, which permits unrestricted use, distribution, and reproduction in any medium, provided the original author and source are credited. 
Here we describe the recovery of NK cells in our cohort of Malaysian HIV patients sampled prospectively during their first year of ART. This is the first study of the recovery of NK cell function in Asian HIV patients beginning ART with advanced immunodeficiency and multiple opportunistic infections. Some patients from the cohort presented with IRD associated with Mtb, cryptococcal, CMV or VZV. These patients are followed individually.

\section{Materials and Methods}

\section{Study subjects}

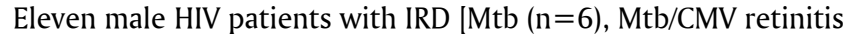
$(\mathrm{n}=1)$, cryptococcal meningitis $(\mathrm{n}=1)$, cryptococcal meningitis/ Kaposi's sarcoma (KS; $n=1)$, CMV retinitis $(n=1)$, dermatomal VZV $(n=1)]$ were identified from a cohort of 100 patients enrolled into an ongoing study of immune reconstitution in patients at the Infectious Disease Outpatient Clinics at University Malaya Medical Centre (UMMC; Kuala Lumpur, Malaysia). Fourteen patients with no evidence of IRD were selected for comparison. These were matched with the IRD patients by sex (male) and ethnicity (Chinese and Malay). All patients received 2 nucleoside analog reverse transcriptase inhibitors (3TC with d4T or AZT) and 1 non-nucleoside reverse transcriptase inhibitors (EFV or NVP). Healthy Chinese and Malay donors $(n=36)$ residing in Kuala Lumpur were included as controls.

Non-IRD patients and healthy controls had no known history of cryptococcal, CMV and VZV disease, but several patients had a history of $\mathrm{Mtb}$, and vaccination with the mycobacterial antigen Bacillus Calmette-Guérin (BCG) is standard practice in Malaysia. HIV patients were slightly older than the healthy controls $(p=0.02)$, but the IRD and non-IRD groups were similar in age $(p=0.35$; Table 1$)$. Institutional ethics approval was obtained for the study and informed consent was given by all participants.

\section{Sample collection, plasma HIV RNA level and $\mathrm{CD}^{+}{ }^{+} \mathrm{T}$-cell counts}

Whole blood was collected into EDTA tubes from patients at baseline and approximately 6, 12, 24 and 48 weeks after commencement of ART, and once from control donors. Peripheral blood mononuclear cells (PBMC) were obtained by Ficoll gradient centrifugation and cryopreserved in liquid nitrogen. Plasma HIV RNA and absolute $\mathrm{CD} 4^{+} \mathrm{T}$-cell counts were assessed before treatment and on 1 or 2 occasions during the first year of ART, by routine clinical laboratories at UMMC. Plasma HIV-1 RNA was measured using the COBAS Amplicor HIV-1 Monitor Test, v1.5 (Roche Diagnostics, Indianapolis, IN, USA). The cutoff defining an undetectable viral load was $<50$ copies $/ \mathrm{ml}$.

\section{IFN $\gamma$ ELISpot assay}

IFN $\gamma$ enzyme-linked immunospot (ELISpot) assay was performed as described [13]. PBMC were stimulated for $20 \mathrm{hr}$ with $\mathrm{K} 562$ cells (effector:target ratio of 10:1), PPD $(10 \mu \mathrm{g} / \mathrm{ml}$; Statens Serum Institute, Copenhagen, Denmark), Cryptococcus neoformans (50 $\mu \mathrm{g} / \mathrm{ml}), \mathrm{CMV}$ and VZV antigens. A mannoprotein preparation of Cryptococcus neoformans, (acapsular strain Cap67) was provided by Dr Stuart M. Levitz (University of Massachusetts Medical School, Worcester, MA, USA) [27]. CMV (strain AD169) and VZV (VARIVAX ${ }^{\mathrm{TM}}$ vaccine, Oka/Merck strain; Merck, Sharp and Dohme; South Granville, NSW, Australia) were cultured in MRC-5 cells, antigens were prepared as described [28] and optimal concentration were determined by IFN $\gamma$ ELISpot using PBMC from sero-positive healthy controls. Spots were counted using AID ELISpot Reader v2.9 software (Autoimmun Diagnostika GmbH, Strassberg, Germany).

\section{Flow cytometry}

Thawed PBMC were washed in $1 \%$ BSA/PBS and $5 \times 10^{5}$ cells were surface stained with CD3-APC, CD16-APC-H7 and CD56-PE (BD Pharmingen, San Jose, CA, USA). To detect intracellular perforin, cells were fixed and permeabilized using Cytofix/Cytoperm Kit ${ }^{\mathrm{TM}}$ (BD Pharmingen) and incubated with Perforin-FITC (BD Pharmingen). Cells were then fixed with $1 \%$ paraformaldehyde before being acquired on a FACSCanto II cytometer (BD Pharmingen). 50,000-100,000 events were recorded per tube and analyzed using the FlowJo program v5.7.2 (Tree Star, Ashland, OR, USA). Gating strategies for NK cell subsets have been described [13].

\section{Statistical analyses}

Mann-Whitney tests were used to compare groups of individuals. As Week 48 samples were not available for some patients, Wilcoxon matched-pair tests were used to compare data from Week 0 and the closest sample to Week 24 to evaluate changes amongst IRD or non-IRD patients during ART. Spearman's test was used to evaluate non-parametric correlation coefficients. For all comparisons, p-values below 0.05 were considered to be statistically significant.

\section{Results}

\section{Clinical and immunological characteristics of the study population, with verification of a response to ART}

The cohort comprised IRD patients, non-IRD patients and healthy controls (Table 1 ). Nadir CD4 ${ }^{+}$T-cell counts were $<110$ cells $/ \mu l$ in IRD and non-IRD patients $(\mathrm{p}=0.40)$. ART increased CD4 T-cell counts $[p<0.0001$ by week $16(11-37)$ in IRD and non-IRD patients] and percentages $[\mathrm{p}<0.005$ by week $24(13-32)$ in IRD and non-IRD patients]. All patients had $>100,000$ copies HIV RNA/ml plasma preART and 24/25 patients suppressed their plasma HIV RNA $(<50-437$ copies/ml) over 9-39 weeks of ART. The remaining patient had no follow-up HIV RNA data, but achieved 12-fold increases in CD4 ${ }^{+} \mathrm{T}$-cell

\begin{tabular}{|c|c|c|c|}
\hline & IRD patients ${ }^{a}$ & Non-IRD patients & Healthy Controls \\
\hline $\mathbf{n}$ & 11 & 14 & 36 \\
\hline Age (years) & $44(34-56)$ & $41(33-64)$ & $36(23-71)^{b}$ \\
\hline 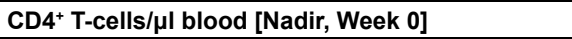 & $22(0-58)$ & $27(0-104)$ & NA \\
\hline 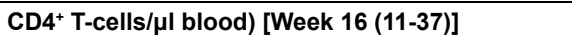 & $142(78-307)$ & $176(54-338)$ & NA \\
\hline$\% \mathrm{CD}^{+}$T-cells of lymphocytes [Week 0] & $2.0(0.5-9.4)$ & $3.9(0.2-10.8)$ & $35.2(20.0-46.4)^{\mathrm{c}}$ \\
\hline$\%$ CD4 $^{+}$T-cells of lymphocytes [Week 24 (13-32)] & $10.2(4.1-15.7)$ & $8.6(2.8-20.5)$ & $35.2(20.0-46.4)^{c}$ \\
\hline
\end{tabular}

Values are presented as median (range), NA = not available

${ }^{a}$ All parameters assessed were similar to non-IRD patients

bower than all HIV patients $(p<0.05)$

cHigher than all HIV patients $(p<0.05)$ 
Citation: Tan DBA, Yong YK, Tan HY, French M, Kamarulzaman A, et al. (2010) Characteristics of Natural Killer Cells in Malaysian HIV Patients Presenting with Immune Restoration Disease After ART. J AIDS Clinic Res 1:102 doi:10.4172/2155-6113.1000102

Page 3 of 7

count ( 22 to 262 cells) after 37 weeks. HIV RNA levels were similar in IRD and non-IRD patients.

All cases of IRD presented as atypical opportunistic infections or inflammatory disease after ART [29]. Four patients experienced 'paradoxical' Mtb IRD defined by treatment for active Mtb disease before ART, followed by lymphadenopathy, lymph nodes evolving into abscesses or cold abscess enlargement on ART. Three patients with no history of Mtb infection pre-ART developed 'unmasking' Mtb IRD, including one who also experienced CMV retinitis as an IRD. Two patients experienced 'unmasking' cryptococcal IRD presenting as cryptococcal meningitis, including one with worsening of Kaposi sarcoma coincident with his cryptococcal IRD. Two patients presented with CMV retinitis as an IRD (one also experienced Mtb IRD) and one patient experienced dermatitis associated with VZV infection after ART.

\section{IRD usually parallel IFN $\gamma$ responses to pathogen antigens}

Most IRD patients showed increased IFN $\gamma$ production against antigens from the provoking pathogens at the time of IRD and for up to 48 weeks. Levels were above the median value of non-IRD patients and healthy controls (Figure 1A, B, D). This was evident with 5/7 Mtb, 2/2 cryptococcal and 1/1 VZV IRD patients. The patient who experienced both CMV and Mtb IRD showed a moderate increase in IFN $\gamma$ responses to CMV during his IRD, whilst the other CMV IRD patient had persistently low responses $(<10$ spots per 200,000 PBMC; Figure 1C)

NK IFN $\gamma$ responses remained impaired after Week 24 in all patients, irrespective of IRD

NK cell IFN $\gamma$ responses were deficient in IRD and non-IRD patients at baseline compared to healthy controls $(p<0.001$; Figure $1 G)$. These increased significantly by Week $24(\mathrm{p}<0.01)$ but remained lower than healthy controls $(\mathrm{p}<0.05)$ and did not resolve after 48 weeks (Figure 1E, 1F). No differences were observed between IRD and non-IRD patients at Week 0 or Week 24 of ART. NK cell IFN $\gamma$ responses remained low in most IRD patients at the time of IRD. One Mtb IRD patient showed a peak in IFN $\gamma$ production during his IRD. Two IRD patients with CMV retinitis (+/- Mtb IRD) and one other Mtb IRD patient showed an increased NK cell IFN $\gamma$ soon after their IRD was diagnosed (Figure 1E). However, several non-IRD patients also displayed elevated NK IFN $\gamma$ responses (Figure 1F).

\section{Proportions of CD56 ${ }^{\mathrm{hi}}$ NK cells increased on ART, with a peak in a few IRD patients}

CD3- lymphocytes were distinguished by expression of CD56 creating NK subsets that can be quantitated as proportions of lymphocytes. CD56 ${ }^{\text {lo }} \mathrm{NK}$ cells are naturally more cytotoxic and express higher levels of CD16 than CD56 ${ }^{\text {hi }} \mathrm{NK}$ cells. CD56 ${ }^{\text {hi }} \mathrm{NK}$ cells are less cytotoxic, express low levels of CD16 and are more able to make cytokines (e.g. IFN $\gamma$ and TNF $\alpha)[13,30]$. NK IFN $\gamma$ responses correlated with proportions of $\mathrm{CD} 56^{\text {lo }}$ NK cells in Australian HIV patients after $>2$ years of ART. Intracellular cytokine staining assay confirmed that $\mathrm{CD}^{\text {lo }}{ }^{\text {NK }}$ cells produced IFN $\gamma$ in response to K562 cells[13].

Here, proportions of CD56 $6^{\text {lo }}$ NK cells were similar across all groups of patients and were relatively stable during one year of ART, irrespective of an IRD (Figure 2A, 2B, 2C). NK IFN $\gamma$ responses correlated with proportions of CD56 ${ }^{\text {lo }} \mathrm{NK}$ cells in Malaysian controls $(r=0.35, p=0.05)$, but not in Malaysian HIV patients at Week 0 or Week $24(\mathrm{r}=0.13, \mathrm{p}=0.56$ and $\mathrm{r}=0.19, \mathrm{p}=0.38$ respectively).

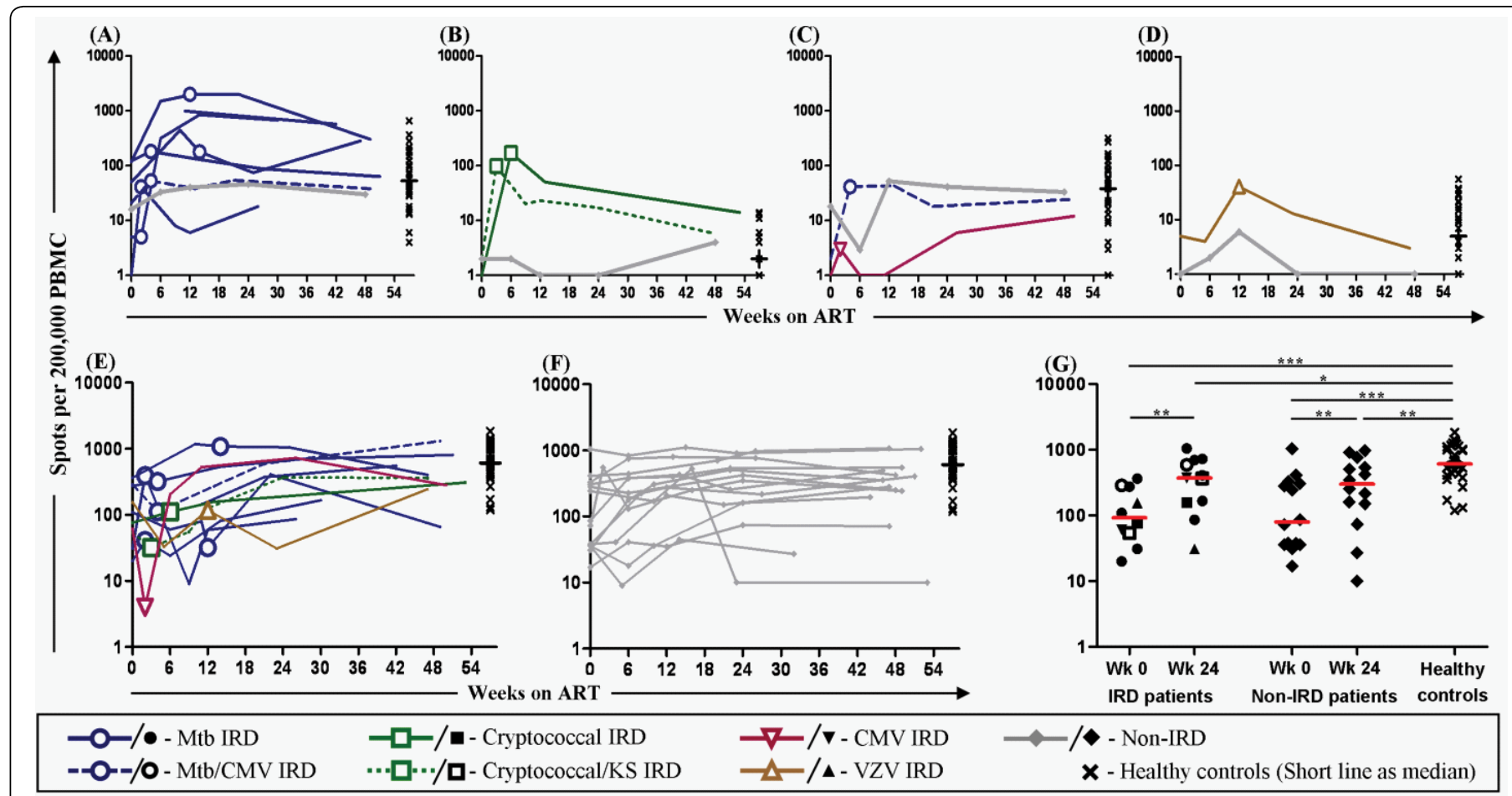

Figure 1: ELISpot analysis of IFN $\gamma$-producing PBMC after stimulation with the following antigens: (A) PPD, (B) Cryptococcus neoformans mannoprotein, (C) CMV lysate and (D) VZV lysate. Median values for non-IRD patients at week 0, 6, 12, 24 and 48 are represented by filled symbols connected by a grey line in each graph. IFN $\gamma$ production against a pan-NK cell target (K562 cells) in PBMC from HIV patients who experienced an IRD (E) and non-IRD patients (F). Cross-sectional comparison of IFN $\gamma$ production against K562 cells between IRD patients, non-IRD patients and healthy controls $(\mathbf{G})$. Horizontal lines represent median values. ${ }^{*}=$ $p<0.05,{ }^{* *}=p<0.01,{ }^{* * *}=p<0.001$. 

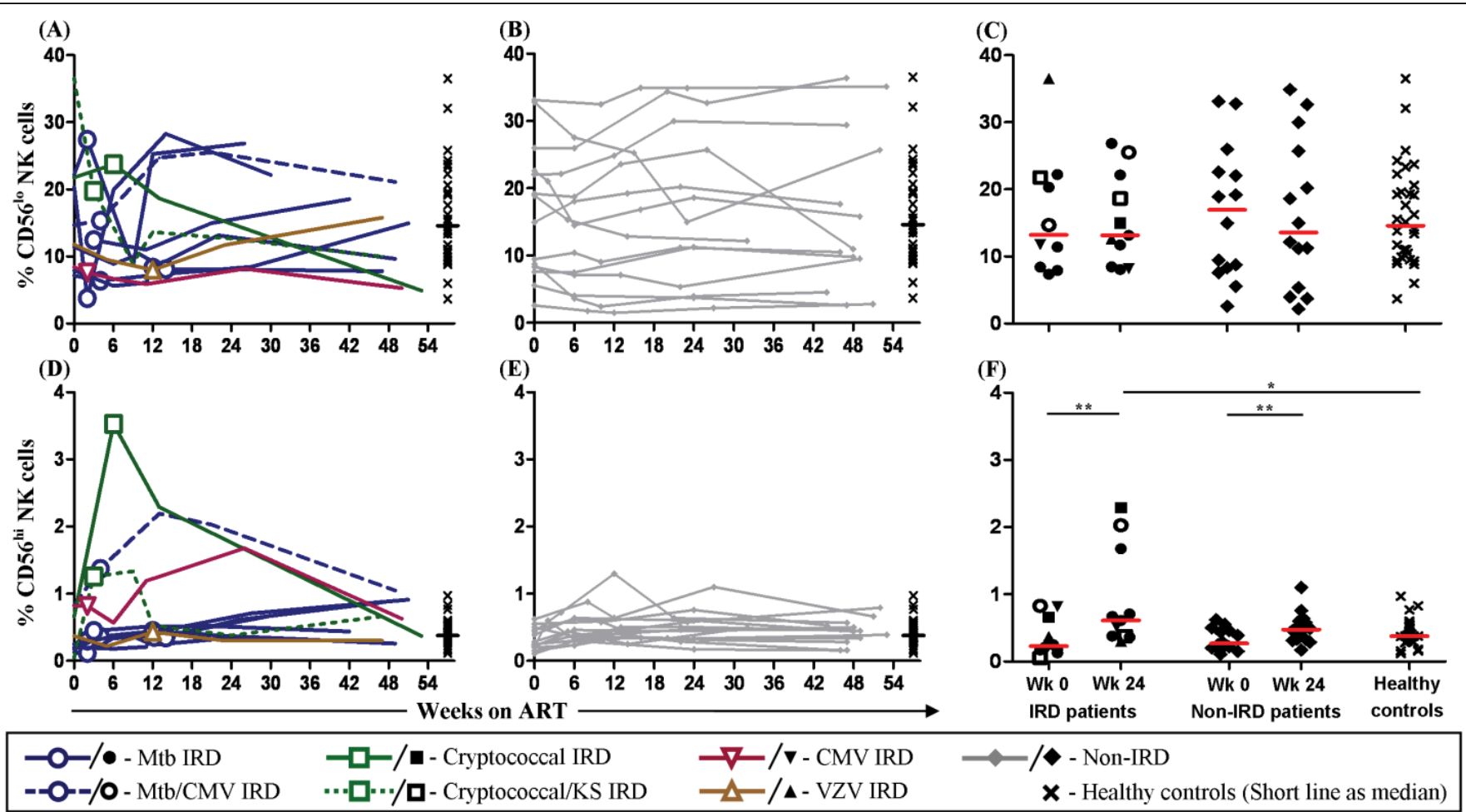

Figure 2: Longitudinal evaluation of proportions of CD56 ${ }^{10}$ NK cells $(A, B, C)$ and CD56 ${ }^{\text {hi }}$ NK cells (D,E,F) in the lymphocyte population of HIV patients who experienced IRD $(\mathbf{A}, \mathbf{D})$ and in non-IRD patients $(\mathbf{B}, \mathbf{E})$. Cross-sectional comparison of NK cell subsets between IRD patients, non-IRD patients and healthy controls $(\mathbf{C}, \mathbf{F})$. Horizontal lines represent median values. ${ }^{*}=p<0.05,{ }^{* *}=p<0.01,{ }^{* * *}=p<0.001$.

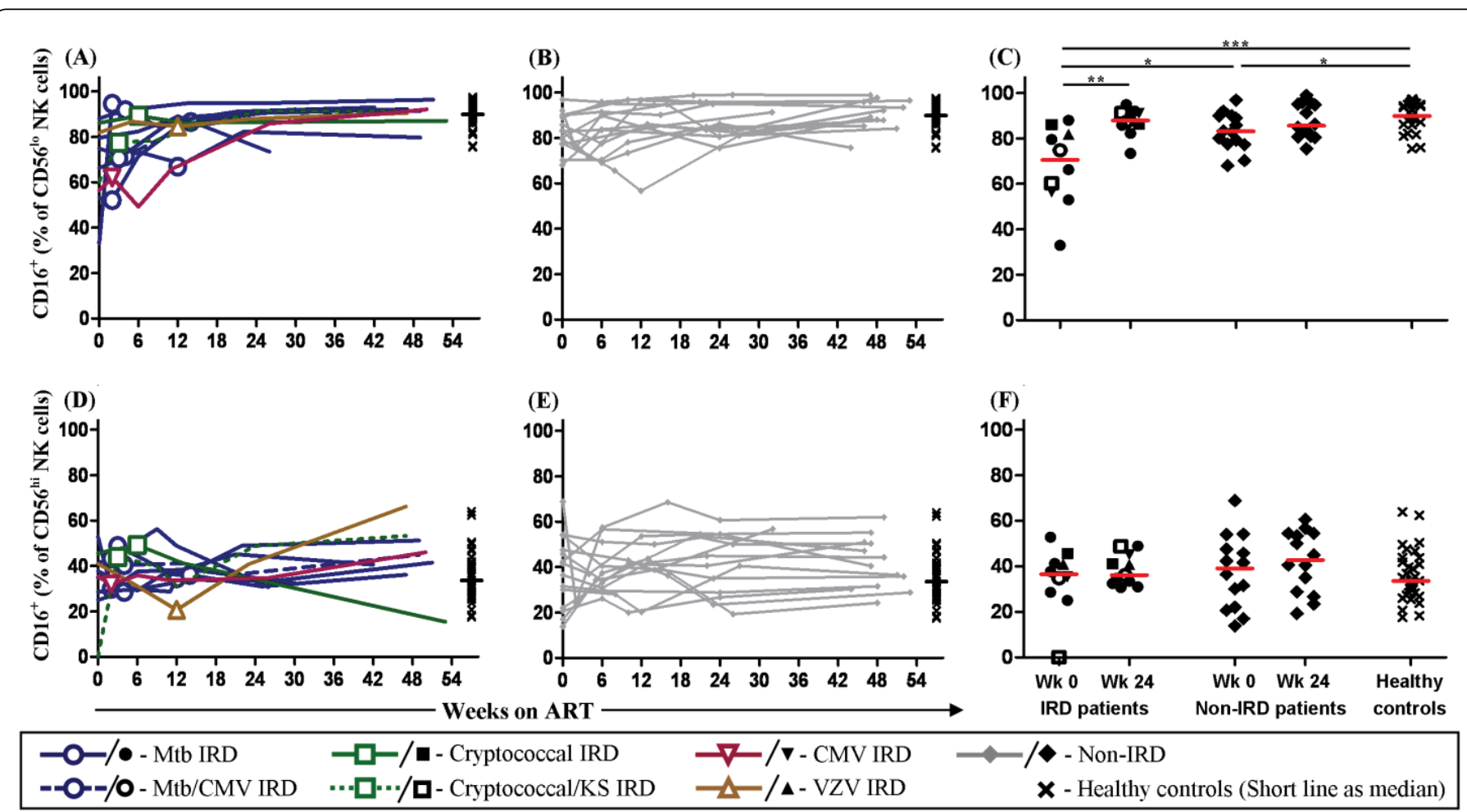

Figure 3: Longitudinal evaluation of CD16 expression on CD56 $6^{\text {to }} \mathrm{NK}$ cells $(\mathbf{A}, \mathbf{B}, \mathbf{C})$ or on CD56 $6^{\text {hi }} \mathrm{NK}$ cells $(\mathbf{D}, \mathbf{E}, \mathbf{F})$ in HIV patients experiencing IRD (A,D) and in nonIRD patients (B,E). Cross-sectional comparison of CD16 expression between IRD patients, non-IRD patients and healthy controls (C,F). Horizontal lines represent median values. ${ }^{*}=p<0.05,{ }^{* *}=p<0.01,{ }^{* \star *}=p<0.001$ 

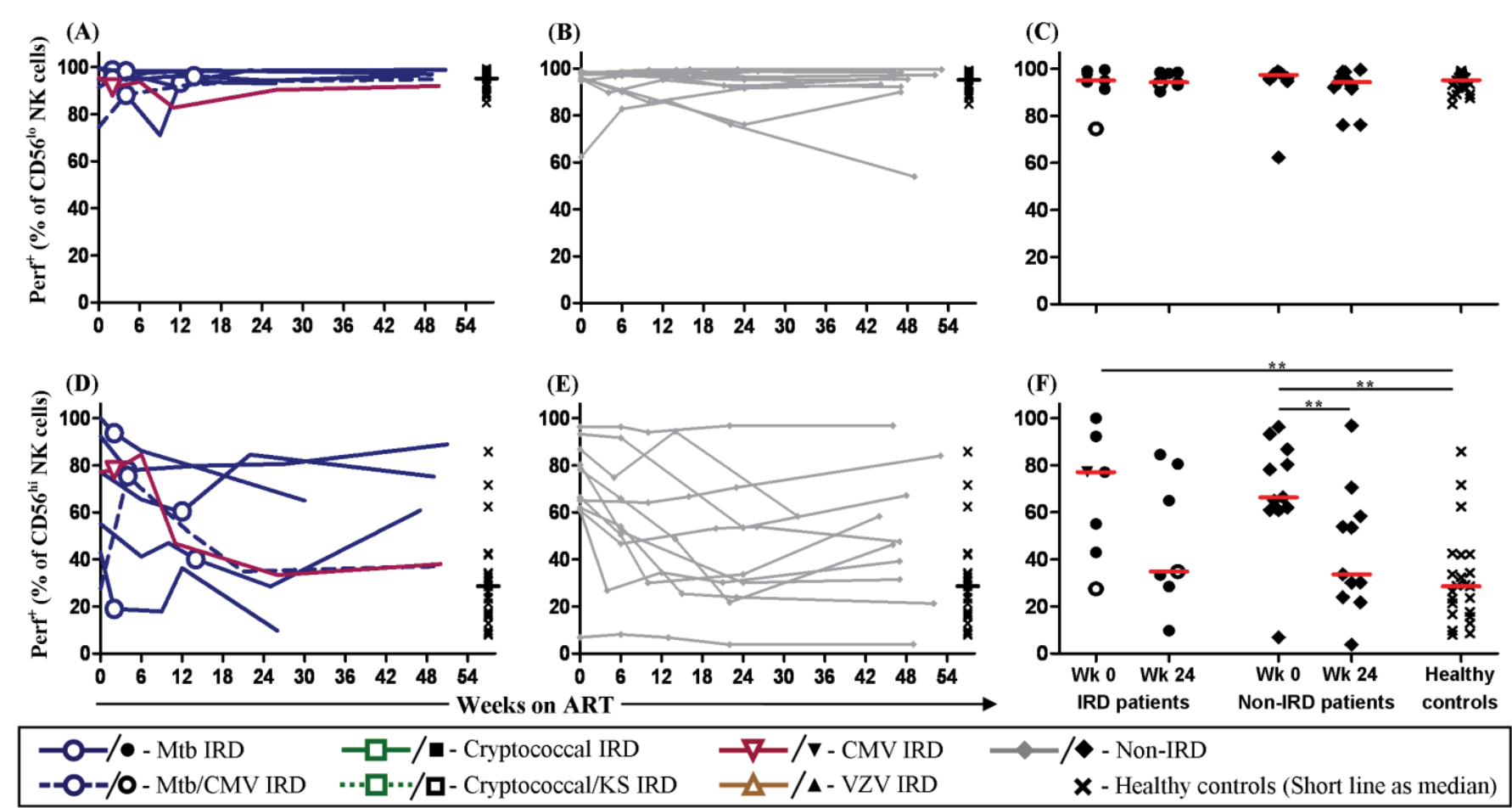

Figure 4: Longitudinal evaluation of perforin expression on CD56 ${ }^{\mathrm{lo}} \mathrm{NK}$ cells $(\mathbf{A}, \mathbf{B}, \mathbf{C})$ or on CD56 ${ }^{\mathrm{hi}}$ NK cells (D,E,F) in HIV patients experiencing IRD (A,D) and in nonIRD patients (B,E). Cross-sectional comparison of perforin expression between IRD patients, non-IRD patients and healthy controls (C,F). Horizontal lines represent median values. ${ }^{*}=p<0.05,{ }^{* *}=p<0.01,{ }^{* * *}=p<0.001$.

Proportions of $\mathrm{CD}^{6} 6^{\text {hi }}$ NK cells increased in IRD and non-IRD patients from Week 0 to Week 24 of ART (Figure 2F, p<0.01). IRD patients had slightly more CD56 $6^{\text {hi }}$ NK cells at Week 24 than healthy controls (Figure 2D, 2F). This pattern held in several patients to Week 48. The two cryptococcal IRD patients showed increased proportions of $\mathrm{CD}^{\mathrm{hi}} \mathrm{HK}^{\mathrm{hi}}$ cells coinciding with peaks in cryptococcal IFN $\gamma$ responses during their IRD (Figure 1B). The two patients with CMV retinitis (+/- Mtb IRD) also showed increased proportions of CD56 ${ }^{\text {hi }}$ NK cells on ART above other patients. The CMV/Mtb IRD patient had higher IFN $\gamma$ responses to CMV (Figure $1 \mathrm{C}$ ) and proportions of CD56 ${ }^{\mathrm{hi}}$ NK cells (Figure 2D).

\section{CD16 expression on $\mathrm{CD}^{\mathrm{lo}} 6^{\mathrm{N}} \mathrm{NK}$ cells was low in most IRD patients at baseline.}

CD16 expression on CD56 ${ }^{\text {lo }} \mathrm{NK}$ cells was lower at baseline in IRD $(\mathrm{p}<0.001)$ and non-IRD patients $(\mathrm{p}<0.05)$ compared to healthy controls (Figure 3A, 3B, 3C) and increased to levels seen in controls by Week 24 (Figure 3C). CD16 expression displayed equivalent trends when assessed as Mean Fluorescence Intensity $(p<0.05$; data not shown). Baseline CD16 expression was lower in IRD patients than nonIRD patients $(p<0.05$; Figure $3 C)$. An examination of the individual plots (Figure 3A) shows that the low baseline values in patients with IRD associated with Mtb $(n=3)$, CMV $(n=1)$ and cryptococcal meningitis/KS $(n=1)$. These IRD occurred whilst CD16 expression was low. In contrast, CD16 expression on CD56 ${ }^{\text {hi }}$ NK cells was similar in all groups and did not reflect individual IRD events (Figure 3D, 3E, 3F).

\section{Expression of perforin on CD56 ${ }^{\text {hi }}$ NK cells was high in all patients}

Intracellular perforin was assessed in seven IRD patients (5 Mtb, $1 \mathrm{Mtb} / \mathrm{CMV}$ and $1 \mathrm{CMV}$ IRD), 10 non-IRD patients and 23 healthy controls. Perforin expression in CD56 ${ }^{\text {lo }}$ NK cells was not deficient in HIV patients at baseline and remained high to Week 48 with no difference between IRD and non-IRD patients (Figure 4A, 4B, 4C). Perforin expression on CD56 ${ }^{\text {hi }} \mathrm{NK}$ cells was higher at baseline in IRD and non-IRD patients $(\mathrm{p}<0.01)$ compared to healthy controls, with a decline by week 24 . Expression remained similar in IRD and non-IRD patients (Figure 4D, 4E, 4F).

\section{Discussion}

Our study establishes that defects in NK cell IFN $\gamma$ responses in Asian HIV patients persist for at least 1 year on ART. The K562 cell line only presents ligands for NK cell activatory receptors [31], so the data reflect maximum NK cell responses - responses to other targets may be even lower. NK cell IFN $\gamma$ responses to K562 cells also remained low in Australian (Caucasian) HIV patients on long-term ART (2-5 years) [13]. Defects in NK cell IFN $\gamma$ responses increase risk of tumors and infections [1-4]. This may explain the increasingly high incidence of non-AIDS-related malignancies seen in patients with optimal stable responses to ART [32].

NK cell IFN $\gamma$ responses were limited by proportions of CD56 ${ }^{\text {lo }}$ NK cells in Australian patients on long-term ART (2-5 years) [13]. Here no correlations were observed with the proportions of CD56 ${ }^{\text {lo }}$ $\mathrm{NK}$ cells or CD56 ${ }^{\text {hi }} \mathrm{NK}$ cells in patients. Expansion of dysfunctional $\mathrm{CD} 6^{\text {neg }} \mathrm{CD} 16^{+} \mathrm{NK}$ cells in HIV viremic patients has been linked to impaired function of the total NK cell population. Compared to $\mathrm{CD}^{+} 6^{+} \mathrm{NK}$ cells, CD56 ${ }^{\text {neg }} \mathrm{CD}^{+} 6^{+} \mathrm{NK}$ cells have poorer cytotoxic function and secrete lower levels of IFN $\gamma$ and TNF $\alpha$ [8]. However we did not quantitate these cells as our antibody panel did not allow us to gate out monocytes.

Perforin expression on $\mathrm{CD} 56^{\text {lo }}$ NK cells was not deficient in the 
Citation: Tan DBA, Yong YK, Tan HY, French M, Kamarulzaman A, et al. (2010) Characteristics of Natural Killer Cells in Malaysian HIV Patients Presenting with Immune Restoration Disease After ART. J AIDS Clinic Res 1:102 doi:10.4172/2155-6113.1000102

Malaysian HIV patients suggesting that the cytotoxic potential of their NK cells is not impaired. Functional assessment of cytotoxic NK cells are warranted as other studies have demonstrated impaired NK cell cytotoxicity in HIV viremic and aviremic patients $[7,12,33]$ Defects affecting the degranulation pathway or receptor recognition may limit NK function, despite normal or elevated levels of perforin. Higher expression of perforin in CD56 ${ }^{\text {hi }}$ NK cells from HIV patients sampled at baseline (Figure 3D) may reflect immune activation as CD56 $6^{\text {hi }}$ NK cells can increase expression of perforin after stimulation with IL-2 [34].

One can envisage mechanisms whereby NK cells may be protective or pathological in an IRD. Studies of mycobacterial and cryptococcal IRD conclude that antigen load is a risk factor for developing IRD [35-37], so NK cells may minimize the risk of developing IRD through their capacity to control mycobacterial, cryptococcal, CMV and VZV infections $[4,38,39]$. Alternatively, excessive NK cell responses restored on ART may contribute to the elevated cytokine responses implicated in IRD pathogenesis[19,22]. Clark et al. [2004] described compartmentalization of NK cell activation to the central nervous system in a patient with neurological VZV IRD [26].

Here, NK IFN $\gamma$ responses only increased before the IRD in one patient (Mtb IRD; Figure 1E), so NK cells are unlikely to contribute cytokines that mediate IRD. No significant changes were observed with the proportion of $\mathrm{CD} 56^{\text {lo }}$ NK cells in circulation during the development of IRD. However, proportions of CD56 $6^{\text {hi }}$ NK cells did increase in the two IRD patients who presented with cryptococcal meningitis coinciding with peaks in cryptococcal IFN $\gamma$ responses during their IRD. These patients were not distinguishable by other parameters such as nadir $\mathrm{CD} 4^{+} \mathrm{T}$-cell count, rate of $\mathrm{CD} 4^{+} \mathrm{T}$-cell recovery or NK IFN $\gamma$ responses (data not shown), so this warrants further investigation as a mechanism of IRD affecting a secluded site (such as the central nervous system).

CD16 (FcrR3a) is an activatory receptor which can mediate antibody-dependent cell cytotoxicity (ADCC) [40]. Here expression of CD16 on $\mathrm{CD}^{2} 6^{\text {lo }} \mathrm{NK}$ cells normalized by Week 24 of ART, which may reflect normal capability to elicit ADCC. CD16 expression on CD56 ${ }^{\text {lo }}$ NK cells was particularly low in IRD patients before ART (Figure 3A). Impaired CD16 expression may affect the recognition, activation and ADCC function of NK cells against antibody-coated pathogens $[41,42]$. This may limit antigen clearance before ART, increasing the risk of IRD. ADCC should be addressed directly in further studies, as the response of NK cells toward K562 cells does not depend on CD16.

In conclusion, we showed partial restoration of NK cell profiles with recovery of $\mathrm{CD} 16$ expression on $\mathrm{CD} 56^{\text {lo }} \mathrm{NK}$ cells and perforin expression on $\mathrm{CD}^{6} 6^{\mathrm{hi}} \mathrm{NK}$ cells to levels of healthy controls after approximately 6 months of ART. However, NK cell IFN $\gamma$ responses remained impaired compared to healthy controls. We found no evidence of a role for NK cells in the pathogenesis of IRD as responses varied between patients with similar IRD, with no consistent peaks preceding diagnosis. However, NK deficiency may promote IRD by impairing antigen clearance before ART as CD16 expression of CD56 ${ }^{\text {lo }}$ NK cells was low at baseline in most IRD patients. This warrants independent replication. Pathogen-infected target cells (e.g. Mtbinfected monocytes or CMV-infected fibroblasts) should be used to investigate responses of NK cells during specific IRD. NK genotypes (eg: KIR) should also be considered.

\section{Acknowledgements}

The authors would like to thank Prof. K.P. Ng for laboratory facilities, $\mathrm{Dr} \mathrm{S}$
Omar and Dr S. Ponnampalavanar for clinical reviews of the patients, Y.M. Lee for technical assistance and the patients and controls who contributed to this study The project was supported by Infectious Diseases Research Fund, UMMC and the National Health and Medical Research council (Grant 513755). This is publication 2010-01 (Clinical Immunology and Immunogenetics, Royal Perth Hospital).

\section{References}

1. Carrington M, Martin MP (2006) The impact of variation at the KIR gene cluster on human disease. Curr Top Microbiol Immunol 298:225-257.

2. Marr KJ, Jones GJ, Zheng C.Huston SM, Timm-McCann M, et al. (2009) Cryptococcus neoformans directly stimulates perforin production and rearms NK cells for enhanced anticryptococcal microbicidal activity. Infect Immun77: 2436-2446.

3. Millman AC, Salman M, Dayaram YK, Connell ND, Venketaraman V (2008) Natural killer cells, glutathione, cytokines, and innate immunity against Mycobacterium tuberculosis. J Interferon Cytokine Res 28:153-165.

4. Lodoen MB, Lanier LL (2006) Natural killer cells as an initial defense against pathogens. Curr Opin Immunol 18:391-398.

5. Alter G, Teigen N, Davis BT, Addo MM, Suscovich TJ, et al. (2005) Sequential deregulation of NK cell subset distribution and function starting in acute HIV-1 infection. Blood 106: 3366-3369.

6. Fauci AS, Mavilio D, Kottilil S (2005) NK cells in HIV infection: paradigm for protection or targets for ambush. Nat Rev Immunol 5:835-843.

7. Mavilio D, Benjamin J, Daucher M, Lombardo G, Kottilil S, et al. (2003) Natural killer cells in HIV-1 infection: dichotomous effects of viremia on inhibitory and activating receptors and their functional correlates. Proc Natl Acad Sci U S A 100:15011-15016.

8. Mavilio D, Lombardo G, Benjamin J, Kim D, Follman D, et al. (2005) Characterization of CD56-/CD16+ natural killer (NK) cells: a highly dysfunctional NK subset expanded in HIV-infected viremic individuals. Proc Natl Acad Sci U S A 102:2886-2891.

9. Chehimi J, Azzoni L, Farabaugh M, Creer SA, Tomescu C, et al. (2007) Baseline viral load and immune activation determine the extent of reconstitution of innate immune effectors in HIV-1-infected subjects undergoing antiretroviral treatment. J Immunol 179: 2642-2650.

10. Alter G, Malenfant JM, Delabre RM, Burgett NC, Yu XG, et al. (2004) Increased natural killer cell activity in viremic HIV-1 infection. J Immunol 173:5305-5311.

11. Azzoni L, Papasavvas E, Chehimi J, Kosman JR, Mounzer K, et al. (2002) Sustained impairment of IFN-gamma secretion in suppressed HIV-infected patients despite mature NK cell recovery: evidence for a defective reconstitution of innate immunity. J Immunol 168:5764-5770.

12. De Maria A, Fogli M, Costa P, Murdaca G, Puppo F, et al. (2003) The impaired NK cell cytolytic function in viremic HIV-1 infection is associated with a reduced surface expression of natural cytotoxicity receptors (NKp46, NKp30 and NKp44). Eur J Immunol 33: 2410-2418.

13. Tan DB, Fernandez S, French M, Price $P$ (2009) Could natural killer cells compensate for impaired CD4+ T-cell responses to CMV in HIV patients responding to antiretroviral therapy?. Clin Immunol 132:63-70.

14. Vermund $\mathrm{SH}$, Yamamoto $\mathrm{N}$ (2007) Co-infection with human immunodeficiency virus and tuberculosis in Asia. Tuberculosis (Edinb) 87: S18-25.

15. Ruxrungtham K, Brown T, Phanuphak P (2004) HIVIAIDS in Asia. Lancet 364 69-82.

16. Lee YC, Chan SH, Ren EC (2008) Asian population frequencies and haplotype distribution of killer cell immunoglobulin-like receptor (KIR)genes among Chinese, Malay, and Indian in Singapore. Immunogenetics 60:645-654.

17. French MA (2009) HIVIAIDS: immune reconstitution inflammatory syndrome: a reappraisal. Clin Infect Dis 48:101-107.

18. Price P, Murdoch DM, Agarwal U, Lewin SR, Elliott JH, et al. (2009) Immune restoration diseases reflect diverse immunopathological mechanisms. Clin Microbiol Rev 22: 651-663.

19. Bourgarit A, Carcelain G, Martinez V, Lascoux C, Delcey V, et al. (2006) Explosion of tuberculin-specific Th1-responses induces immune restoration syndrome in tuberculosis and HIV co-infected patients. Aids 20: F1-7.

20. Elliott JH, Vohith K, Saramony S, Savuth C, Dara C, et al. (2009) Immunopathogenesis and diagnosis of tuberculosis and tuberculosisassociated immune reconstitution inflammatory syndrome during early antiretroviral therapy. J Infect Dis 200:1736-1745. 
Citation: Tan DBA, Yong YK, Tan HY, French M, Kamarulzaman A, et al. (2010) Characteristics of Natural Killer Cells in Malaysian HIV Patients Presenting with Immune Restoration Disease After ART. J AIDS Clinic Res 1:102 doi:10.4172/2155-6113.1000102

Page 7 of 7

21. Meintjes G, Wilkinson KA, Rangaka MX, Soklimowska K, Van Veen K, et al. (2008) Type 1 helper T cells and FoxP3-positive T cells in HIV-tuberculosisassociated immune reconstitution inflammatory syndrome. Am J Respir Crit Care Med 178: 1083-1089.

22. Tan DB, Yong YK, Tan HY, Kamarulzaman A, Tan LH, et al. (2008) Immunological profiles of immune restoration disease presenting as mycobacterial lymphadenitis and cryptococcal meningitis. HIV Med 9:307-316

23. Price $P$, Witt $C$, de Santis D, French MA (2007) Killer immunoglobulin-like receptor genotype may distinguish immunodeficient HIV-infected patients resistant to immune restoration diseases associated with herpes virus infections. J Acquir Immune Defic Syndr 45: 359-361.

24. Caligiuri MA (2008) Human natural killer cells. Blood 112: 461-469.

25. Henel G, Singh K, Cui D, Pryshchep S, Lee WW, et al. (2006) Uncoupling of T-cell effector functions by inhibitory killer immunoglobulin-like receptors. Blood 107: 4449-4457.

26. Clark BM, Krueger RG, Price P, French MA (2004) Compartmentalization of the immune response in varicella zoster virus immune restoration disease causing transverse myelitis. Aids 18:1218-1221.

27. Mansour MK, Schlesinger LS, Levitz SM (2002) Optimal T cell responses to Cryptococcus neoformans mannoprotein are dependent on recognition of conjugated carbohydrates by mannose receptors. J Immunol 168: 2872-2879.

28. Keane NM, Price P, Stone SF, John M, Murray RJ, et al. (2000) Assessment of immune function by lymphoproliferation underestimates lymphocyte functional capacity in HIV patients treated with highly active antiretroviral therapy. AIDS Res Hum Retroviruses 16: 1991-1996.

29. French MA, Price P, Stone SF (2004) Immune restoration disease after antiretroviral therapy. Aids 18: 1615-1627.

30. Cooper MA, Fehniger TA, Caligiuri MA (2001) The biology of human natural killer-cell subsets. Trends Immunol 22: 633-640.

31. Garcia-Penarrubia P, Lorenzo N, Galvez J, Campos A, Ferez X, et al. (2002) Study of the physical meaning of the binding parameters involved in effectortarget conjugation using monoclonal antibodies against adhesion molecules and cholera toxin. Cell Immunol 215: 141-150.

32. Crum-Cianflone N, Hullsiek KH, Marconi V, Weintrob A, Ganesan A, et al.
(2009) Trends in the incidence of cancers among HIV-infected persons and the impact of antiretroviral therapy: a 20-year cohort study. Aids 23: 41-50.

33. Fogli M, Costa P, Murdaca G, Setti M, Mingari MC, et al. (2004) Significant NK cell activation associated with decreased cytolytic function in peripheral blood of HIV-1-infected patients. Eur J Immunol 34: 2313-2321.

34. Ferlazzo G, Thomas D, Lin SL, Goodman K, Mordani B, et al. (2004) The abundant NK cells in human secondary lymphoid tissues require activation to express killer cell Ig-like receptors and become cytolytic. J Immunol 172:14551462.

35. de Boer MG, Kroon FP, Kauffmann RH, Vriesendorp R, Zwinderman K, et al (2003) Immune restoration disease in HIV-infected individuals receiving highly active antiretroviral therapy: clinical and immunological characteristics. Neth $J$ Med 61: 408-412.

36. Lawn SD, Wilkinson RJ, Lipman MC, Wood R (2008) Immune reconstitution and "unmasking" of tuberculosis during antiretroviral therapy. Am J Respir Crit Care Med 177: 680-685.

37. Shelburne SA3rd, Darcourt J, White AC Jr, Greenberg SB, Hamill RJ, et al. (2005) The role of immune reconstitution inflammatory syndrome in AIDS-related Cryptococcus neoformans disease in the era of highly active antiretroviral therapy. Clin Infect Dis 40:1049-1052.

38. Ma LL, Wang CL, Neely GG, Epelman S, Krensky AM, et al. (2004) NK cells use perforin rather than granulysin for anticryptococcal activity. J Immunol 173 3357-3365.

39. Vankayalapati R, Garg A, Porgador A, Griffith DE, Klucar P, et al. (2005) Role of NK cell-activating receptors and their ligands in the lysis of mononuclear phagocytes infected with an intracellular bacterium. J Immunol 175: 4611-4617.

40. Sun PD (2003) Structure and function of natural-killer-cell receptors. Immunol Res 27: 539-548.

41. Miller MF, Mitchell TG, Storkus WJ, Dawson JR (1990) Human natural killer cells do not inhibit growth of Cryptococcus neoformans in the absence of antibody. Infect Immun 58: 639-645.

42. Orange JS, Brodeur SR, Jain A, Bonilla FA, Schneider LC, et al. (2002) Deficient natural killer cell cytotoxicity in patients with IKK-gamma/NEMO mutations. J Clin Invest 109: 1501-1509. 